\title{
INVESTIGATION OF EPOXY POWDER COATED GALVANIZED STEEL SUBSTRATE THROUGH ELECTROSTATIC POWDER COATING SYSTEM
}

\author{
R. Ahmad* and M.R. Ajer \\ Department of Manufacturing and Industrial Engineering, \\ Faculty of Mechanical and Manufacturing Engineering, \\ Universiti Tun Hussein Onn Malaysia, \\ 86400 Parit Raja, Batu Pahat, Johor, Malaysia \\ Email: roslee@uthm.edu.my \\ Phone: +6074564103; Fax: +6074536080
}

\begin{abstract}
This research deals with the optimization of an electrostatic powder coating by optimizing the combination of total volume of air with the powder output. Generally, the coating's thickness and uniformity are not at the optimum level. A thicker coating does not necessarily provide a good surface quality. This phenomenon is caused by the insufficient volume of air to support the powder reaching the workpiece. Furthermore, too much air also causes the air to blow off the powder on the workpiece. This research aims to identify the optimum combinations of variable parameters to produce the optimum thickness with the best quality by improving the transfer efficiency and specifically to minimize the amount of powder usage. The evaluation methods used to determine the level of coating quality were thickness measurement, Buchholz indentation test, cross-cut test, color visual and surface structure analysis. The instruments used to evaluate the testing samples were a coating thickness gauge, Buchholz indentor, multi-blade cutting tools, spectrophotometer and Scanning Electron Microscope. The optimum level was found when using the optimum combination of powder output and total air volume, which produced a complete single layer of coating film, having good quality in terms of thickness, adhesion, uniformity, indentation resistance and surface structure.
\end{abstract}

Keywords: Electrostatic powder coating; total air volume; powder output.

\section{INTRODUCTION}

Coating thickness plays a key role in affecting other characteristics such as color visual, indentation resistance, particle cross-linking, adhesion and surface profile. The ability of the variable parameters to affect coating thickness, color visual, particle cross-linking structure, surface texture, indentation resistance and adhesion of the electrostatic powder coating quality was investigated. The first pass transfer efficiency (FPTE) and film uniformity in a corona charging powder spray process were dependent on total air volume, powder output, powder properties and spray gun voltage[1-3]. The total air volume was used as a medium to transfer the powder from the fluidizing bed to the coating target surface. For a uniform mass flow of the powder, the powder must be well dispersed, thus providing a dilute phase flow $[2,4]$. Airflow and the aerodynamic force play a very important role in transporting particles from the spray gun to the region near the coated part[3]. When the particles are in the region near the coated part, the 
electrostatic force plays a key role in depositing the particles onto the coating target surface[4]. A relatively high air volume and associated turbulences hinder the deposition of paint particles from reaching close to the target surface[5, 6]. The total air volume affects not only the penetration of powders into the recessed area of the coated object, but also the transfer efficiency of the coating system [7]. The powders are sprayed with higher total air volume to improve the penetration. However, too high total air volume blows off the powder particles from the surface of the powder layer deposited on the coating object. The transporting air must be strong enough to guide the particles in the direction of the spray, but the particles will lose their momentum when approaching the target surface and this is where the electrostatic force should be dominant for higher deposition rates[8, 9]. The gun-to-part distances also affected the powder FPTE and coating quality[10,11]. Distances of 3 to 12 inches provided the desired results, depending on the nozzle type, part configuration and number of guns used[12]. The powder pump delivery rate and total air volume were properly adjusted to deliver the powder with minimal powder overspray. The relationship between the transfer efficiency of the powder coating process and gun current for a fixed powder output combined with fixed total air volume and spraying distances of 3, 6 and 12 inches was investigated $[13,14]$. The number of free ions flowing to the part for a gunto-part distance of 3 inches was significantly greater than the number of ions flowing to the part at a gun-to-part distance of 10 inches. Maximum transfer efficiency for the spraying distances of 6 to 12 inches was achieved when using $100 \mathrm{kV}$. At the 3 -inch distance between the gun and part, the maximum transfer efficiency was reached at 60 $\mathrm{kV}[12-14]$. The methods of coating powder are fluidized-bed coating, electrostatic fluidized-bed coating and electrostatic spray coating[15-17]. For the fluidized-bed coating, the products, which are preheated above the melt temperatures of the powder, are dipped into the fluidized bed. The powder melts and fuses into a continuous coating. This coating method is used to apply heavy coating in one dip with 75-250 $\mu \mathrm{m}$ thickness. It is possible to build a film thickness of $2.5 \mathrm{~mm}$ using higher preheat temperatures and multiple dips[15]. The product size is limited and inside corners have low film thickness, owing to the well-known Faraday cage effect. The electrostatic fluidized bed is suited to substrates that have relatively small vertical dimensions[16]. It is able to coat some objects such as flat sheets on one side only, as opposed to the conventional fluidized bed that requires dipping of the entire parts.

Electrostatic spray coating is the most widely utilized method for the application of powder coatings[17]. In a typical high voltage system, powder is maintained in a fluidized-bed reservoir, injected into an air stream and carried to the gun where it is charged by passing through a corona discharge field. The charged powder is transported to the grounded part to be coated through a combination of electrostatic and aerodynamic forces. The powder is held by electrostatic forces to the surface of the substrate, which is subsequently heated in an oven where the particles fuse and form a continuous film. This method is suitable to create a low film thickness and good coating appearances. A final solid, tough, abrasion-resistant coating can be obtained. The efficiency of the process can be increased to $95 \%$ of material usage by collecting the powder. The thickness of the coating is between 30 and $75 \mu \mathrm{m}$. Parts with difficult shapes can be coated using this method. The color can be changed relatively simply.

In this paper, electrostatic spraying coating was used to coat the galvanized substrate. It has many advantages compared with other coating methods. It is possible to coat complex parts with low film thickness and have good coating quality. The experimental investigation was carried out to investigate the effect of the optimum combination of 
parameters, such as powder output, total air volume and spraying distances, on FPTE and coating quality. A number of papers have investigated the powder output, total air volume or spraying distances[1-5]. However, no papers have investigated combinations thereof. Even when the powder output is optimum, it must be supported with the optimum total air volume to ensure that the powder has maximum first pass transfer efficiency[1-3]. Thus, the aim of this paper is to investigate the optimum combination of powder output and total air volume of electrostatic powder coating, with which to produce a complete single layer of coating film, having good quality in terms of thickness, adhesion, uniformity, indentation resistance and surface structure.

\section{MATERIALS AND METHODS}

In this research, the electrostatic spray coating was employed with epoxy powder. The charging system method used a high-voltage generator to bring an electrostatic charge onto the powder particles through the intermediate process of creating oxygen ions. The sample size was $400 \mathrm{~mm}$ x $400 \mathrm{~mm}$ galvanized steel. The samples underwent the main processes, such as pre-treatment, dry-off, powder spray and curing.

\section{Experimental Investigation}

The process flow to coat the sample is shown in Figure 1. The samples were hung on the conveyor and moved automatically at a speed of $2.8 \mathrm{~m} / \mathrm{min}$. Before coating the workpieces, all impurities such as grease, oil and dirt, were cleaned off. The cleaning process took place in the multi-zone pre-treatment system. Galvanized steel was treated and slightly pickled to improved adhesion. By means of the conveyor system, the workpieces were guided through the different treatment sections, where chemicals (slightly alkaline) were used to treat the parts. After passing all the pre-treatment zones on the conveyor system, residual humidity was eliminated in the dry-off oven to have good adhesion of powder application. The dry-off oven reached temperatures up to $150^{\circ} \mathrm{C}$. Then the powder was sprayed onto the parts using a flat nozzle electrostatic powder coating system. Subsequent to the powder application, the workpieces were transferred directly into the curing oven. The curing oven temperature was $180^{\circ} \mathrm{C} \pm$ $5^{\circ} \mathrm{C}$.

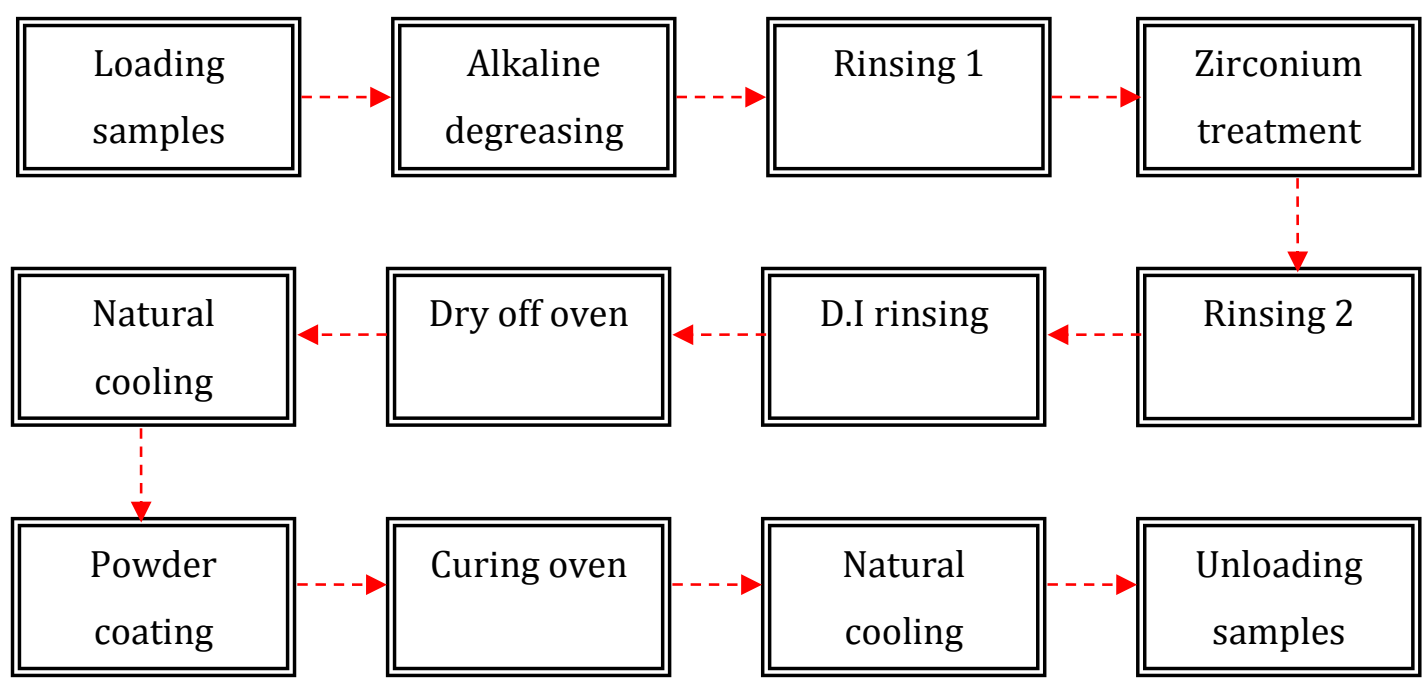

Figure 1. Block diagram for electrostatic powder coating process. 


\section{Evaluation Method}

The cured powder coating film was evaluated for a wide range of characteristics. The methods used to evaluate the coating quality are shown in Figure 2. The thickness of the coated layer was measured to determine the optimum thickness and uniformity of the coated sample. The thickness needed was determined by the amount of protection needed, the required appearance and cost. The procedures to evaluate the coating thickness were based on ISO 2178 standard. The color tone of the coated samples was evaluated using CIE Lab color.

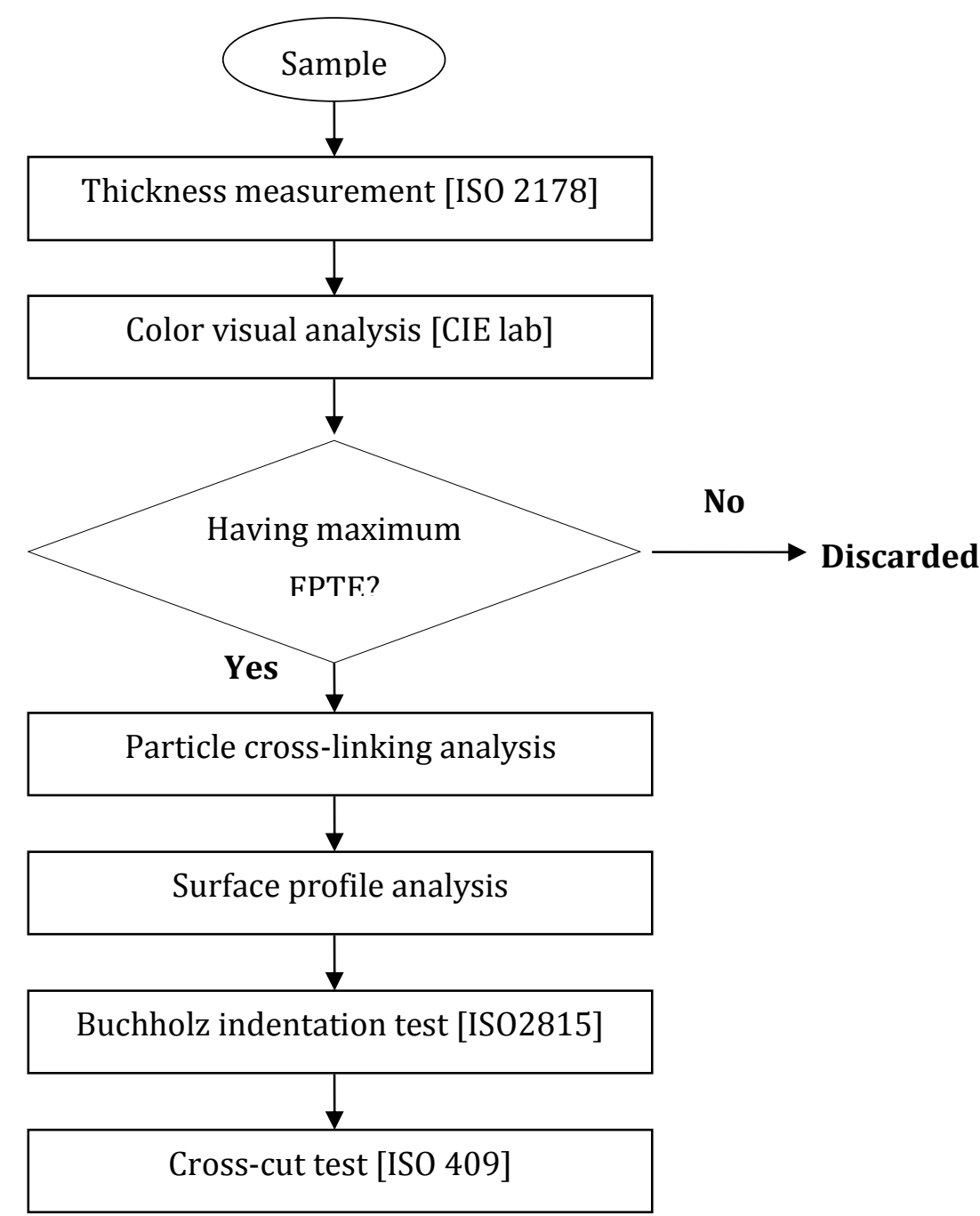

Figure 2. Testing and evaluation procedures for the coated samples.

The CIE Lab color is based on the concept that colors can be considered as combinations of red and yellow, red and blue, green and yellow, and green and blue. $\Delta \mathrm{E}$ is a single number that represents the distance between two colors. $\Delta E^{*} a b$ indicates the color difference represented using numbering. The equipment used to measure the $\Delta E^{*} a b$ is a spectrophotometer. The formula to calculate $\Delta E^{*} a b$ is as follows:

$$
\Delta E * a b=\longdiv { ( \Delta L ^ { * } ) ^ { 2 } + ( \Delta \mathrm { a } ^ { * } ) ^ { 2 } + ( \Delta \mathrm { b } ^ { * } ) ^ { 2 } }
$$


where $\Delta=$ Sample - Standard

$\Delta E$ is a single number that represents the distance between two colours.

$\Delta E^{*} a b$ means the color difference represented using numbering.

Particle cross-linking structure analysis was carried out to investigate the structure of the coated film. Powder particles must be completely linked with others to avoid any defects such as the orange peel effect, insufficient powder coverage and a rough surface. The equipment used to investigate the particle cross-linking structure was a Scanning Electron Microscope (SEM). A cross-cut test was used to assess the resistance of paint coatings to separation from substrates when a right-angled lattice pattern was cut into the coating, penetrating through to the substrate. The apparatus used to carry out the test included multi-blade cutting tools, adhesive tape, a soft brush, viewing lens and stopwatch. The testing procedure to carry out the cross-cut test was based on ISO 2409 standard. The Buchholz indentation test is a method for carrying out an indentation test on a single coating system of paint using a Buchholz indentor. The length of the indentation produced is an indicator of the residual deformation of the coating. The testing procedure to carry out this indentation test was based on ISO 2815 standard. Table 1 shows the size of sample with the combination of powder output and total air volume.

Table 1. Size of samples and the processing parameters.

\begin{tabular}{cccccc}
\hline $\begin{array}{c}\text { Sample } \\
\text { No }\end{array}$ & $\begin{array}{c}\text { Powder } \\
\text { output } \\
(\%)\end{array}$ & $\begin{array}{c}\text { Total air } \\
\text { volume } \\
\left(\mathrm{Nm}^{3} / \mathrm{h}\right)\end{array}$ & $\begin{array}{c}\text { Sample } \\
\text { No }\end{array}$ & $\begin{array}{c}\text { Powder } \\
\text { output } \\
(\%)\end{array}$ & $\begin{array}{c}\text { Total air } \\
\text { volume } \\
\left(\mathrm{Nm}^{3} / \mathrm{h}\right)\end{array}$ \\
\hline 1 & 55.0 & 3.0 & 14 & 65.0 & 6.0 \\
2 & 55.0 & 4.0 & 15 & 65.0 & 7.0 \\
3 & 55.0 & 5.0 & 16 & 70.0 & 3.0 \\
4 & 55.0 & 6.0 & 17 & 70.0 & 4.0 \\
5 & 55.0 & 7.0 & 18 & 70.0 & 5.0 \\
6 & 60.0 & 3.0 & 19 & 70.0 & 6.0 \\
7 & 60.0 & 4.0 & 20 & 70.0 & 7.0 \\
8 & 60.0 & 5.0 & 21 & 75.0 & 3.0 \\
9 & 60.0 & 6.0 & 22 & 75.0 & 4.0 \\
10 & 60.0 & 7.0 & 23 & 75.0 & 5.0 \\
11 & 65.0 & 3.0 & 24 & 75.0 & 6.0 \\
12 & 65.0 & 4.0 & 25 & 75.0 & 7.0 \\
13 & 65.0 & 5.0 & & & \\
\hline
\end{tabular}

\section{RESULTS AND DISCUSSION}

\section{Effect of Powder Output on the Powder FPTE and Coating Thickness}

Figure 3 shows the influence of the powder output and its effects on the thickness and color visual. When the powder output increased, the thickness of the coated film also increased, as observed in Figure 3. Higher powder output enhances the opportunity for the powder to stick to the workpiece. Figure 3 shows that higher powder output produced thicker coating film. However, it does not ensure that the transfer efficiency of the powder is at the maximum level. This is because the transfer efficiency is a 
comparison of the amount of powder that contributes to the film on the part with the total amount of powder sprayed [1]. Furthermore, by increasing the powder output, the values of color visual were decreased. When the value was near to zero, it means that the color was not much different from the reference color defined by the CIE lab system. This shows that the coated film thickness was able to hide the raw material color. The specification for the value of color visual is from 0 to 1.0. Figure 3 shows that the values of color visual for all samples are within the specification.

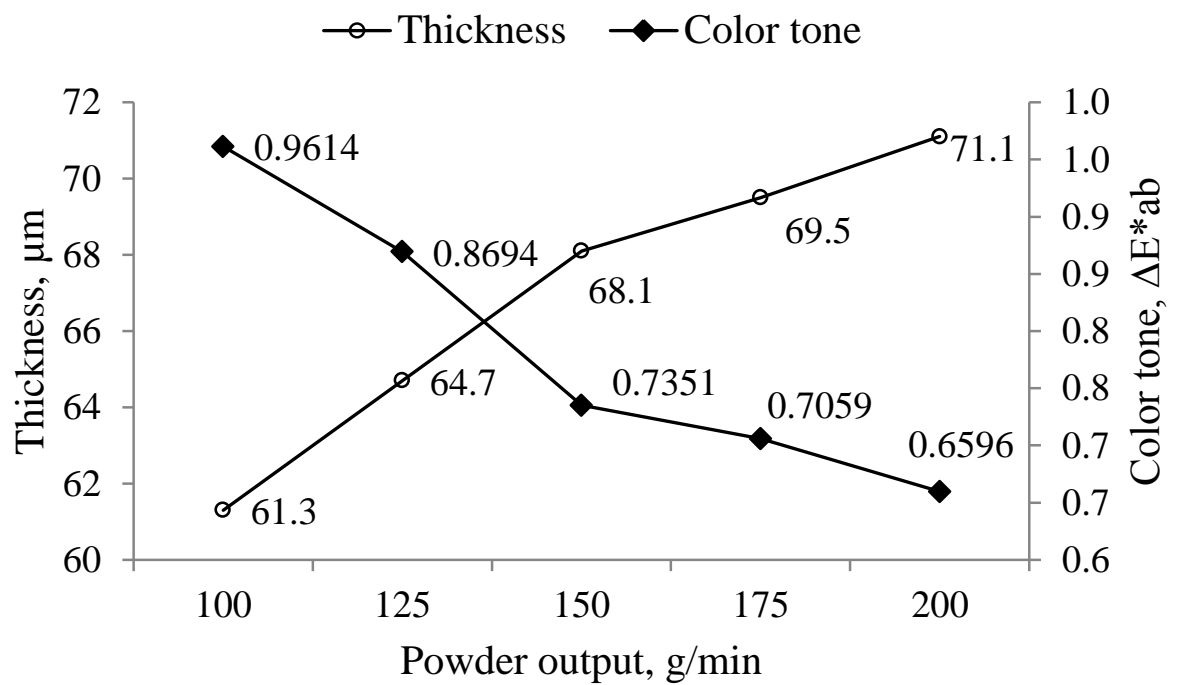

Figure 3. Influence of the powder output and its effects on the thickness and color visual.

\section{Effect of the Total Air Volume on the Powder FPTE and Coating Thickness}

Five samples were tested with total air volume as a variable and two fixed parameters: powder output and spraying distance. Total air volume was set from $3.0 \mathrm{Nm}^{3} / \mathrm{h}$ to 7.0 $\mathrm{Nm}^{3} / \mathrm{h}$. Figure 4 shows the influence of the total air volume and its effects on the thickness and color visual. Figure 4 shows that when the total air volume increased, the thickness was initially increased and then decreased after reaching the optimum level. Samples 6 to 10 used 150 gram/min of powder output, which must be supported with $4.0 \mathrm{Nm}^{3} / \mathrm{h}$ of total air volume. This is because this combination of parameter settings produced the maximum transfer efficiency of powder to the parts. When $3.0 \mathrm{Nm} / / \mathrm{h}$ of total air volume is used, it is not enough to support the powder to reach the parts. Low total air volume caused the powder to fall down before reaching the parts. This is due to the gravity force that dominates the aerodynamic force. However, higher total air volume does not ensure that maximum transfer efficiency can be achieved. Figure 4 shows that when the total air volume increased from 5.0 to $7.0 \mathrm{Nm} / \mathrm{h}$, the thickness decreased. This is because too much air caused the powder to reach the parts with very high pressure that can then blow off the powder deposited on the parts. The total air volume must be optimum to avoid decreasing the transfer efficiency and specifically to prevent blowing off some of the powder deposited on the object [1-3]. 


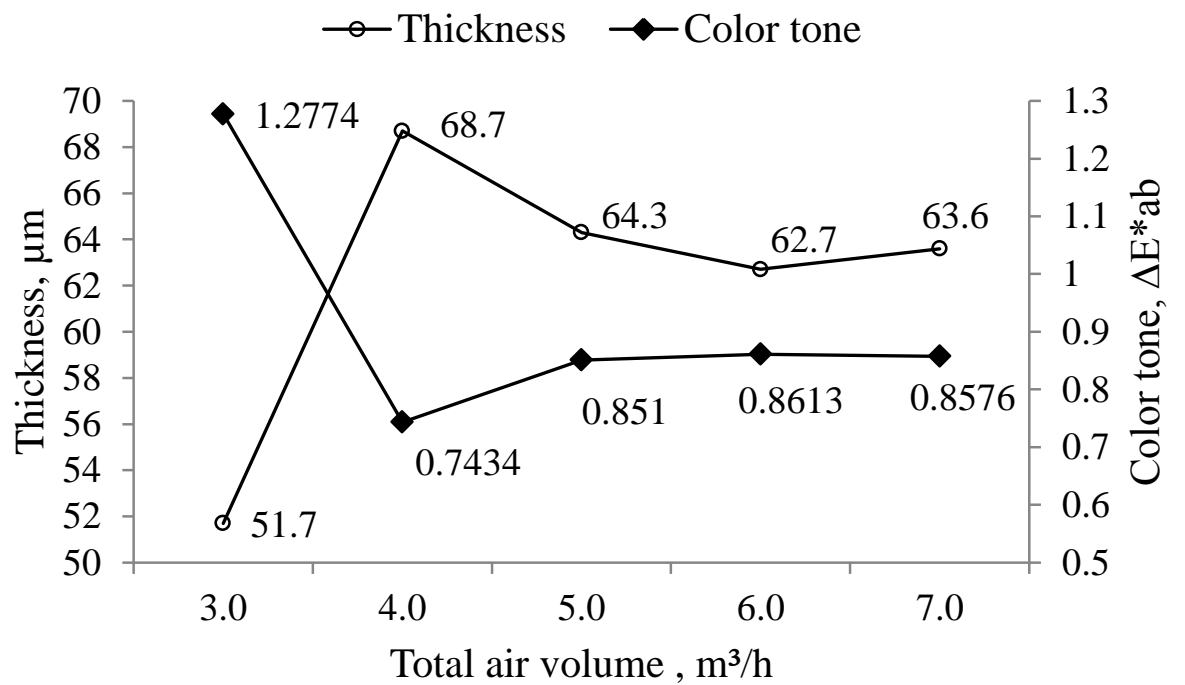

Figure 4. The influence of the total air volume and its effects on the film thickness and color visual.

\section{Effects of the Spray Distance to the Powder FPTE and Coating Thickness}

The distance was set from 12 to $20 \mathrm{~cm}$. The gun cannot be held too close to the part. For safety purposes, the distance must not be less than $10 \mathrm{~cm}$. The powder output was $150 \mathrm{~g} / \mathrm{min}$ and the total air volume was $4.0 \mathrm{Nm}^{3} / \mathrm{h}$. It was combined with different spraying distances.

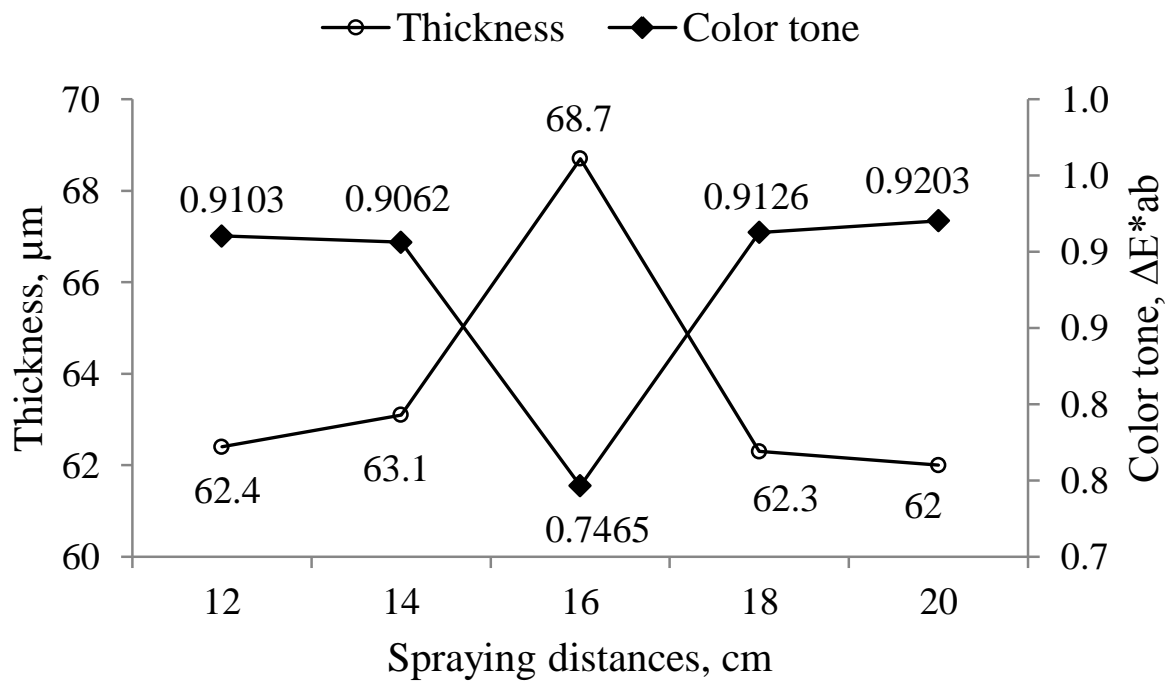

Figure 5. Influence of spraying distance and its effects on thickness and color visual.

Figure 5 shows the influence of spraying distance and its effects on thickness and color visual. The thickness and color visual values were not much different for all setting conditions. Spraying distance is a variable parameter that can affect the transfer efficiency and coating quality. However, this parameter does not significantly affect the 
coating characteristics. This shows that the optimum level of coating film thickness and coating quality can be achieved by optimizing the combination of powder output and total air volume, even with different spraying distances. The maximum transfer efficiency for the spraying distances of 6 to 12 inches was achieved when using $100 \mathrm{kV}$. At the 3-inch distance between the gun and part, the maximum transfer efficiency was reached at $60 \mathrm{kV}[13,14]$.

\section{Optimum combination of the powder output and total air volume}

In this research, 25 samples were tested using different combinations of powder output and total air volume. The combination of these two parameters obtained various responses. The responses were film thickness, color visual, indentation resistance, adhesion, powder cross-linking structure and surface profile.

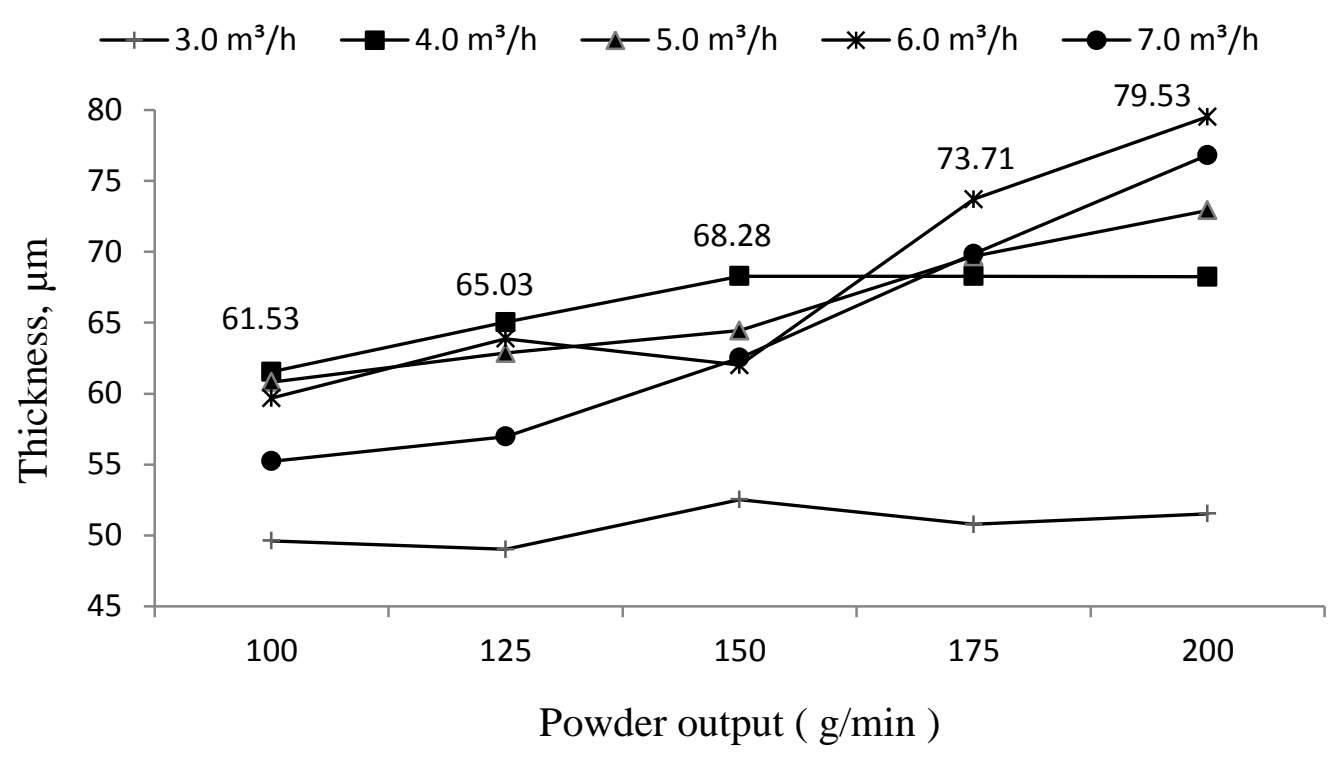

Figure 6. Thickness of the coating film for different combinations of powder output and total air volume.

\section{Effects on Coating Thickness using Different Combinations of Powder Output and Total Air Volume}

Coating film build-up of greater than 60 micron was required to obtain an acceptable smooth film. Figure 6 shows the thickness of coating film for different combinations of powder output and total air volume. The optimum total air volume used to support 100 to $150 \mathrm{~g} / \mathrm{min}$ of powder was $4.0 \mathrm{Nm}^{3} / \mathrm{h}$. This shows that the samples have higher thickness compared with others. The thickness was decreased when spraying the powder using $3.0 \mathrm{Nm}^{3} / \mathrm{h}$. The air volume was not sufficient to support the powder to reach the parts. Some of the powder fell down before reaching the parts. The thickness and transfer efficiency were decreased when spraying using more than $4.0 \mathrm{Nm}^{3} / \mathrm{h}$. This is due to the fact that the powder reaches the parts with high pressure, which prevented the charge powder being attracted to the parts. The powders were scattered and not focused on target. However, the high amount of powder output must be supported by 
higher total air volume. The optimum total air volume used to support 175 to $200 \mathrm{~g} / \mathrm{min}$ of powder was $6.0 \mathrm{Nm}^{3} / \mathrm{h}$. The thickness was not increased when $4.0 \mathrm{Nm}^{3} / \mathrm{h}$ was used. The same thickness was also achieved when $150.0 \mathrm{~g} / \mathrm{min}$ of powder output was used. This means that only a certain amount of powder can reach the parts. The remaining powder fell down before reaching the workpiece. The finding from the previous paper shows that the FPTE can be increased by spraying the powder with a higher total air volume to improve the penetration. However, too high total air volume blows off the powder particles from the surface of the powder layer deposited on the object[1-3].

\section{Effects on Color Visual using Different Combinations of Powder Output and Total Air Volume}

Figure 7 shows the color visual $\left(\Delta E^{*} a b\right)$ for different combinations of powder output and total air volume. Higher thickness was achieved when $\Delta E^{*} a b$ was close to zero. This is because thicker coating film is able to mask the pattern on the sample surface. Thin coating causes the value of $\Delta E^{*} a b$ to deviate far from zero. Furthermore, spraying of any amount of powder output using $3.0 \mathrm{Nm}^{3} / \mathrm{h}$ produced a thin coating and the value of $\Delta E^{*} a b$ was out of specification. This is because the sample has poor powder coverage and certain areas still have raw material color. It needs to be recoated to get $\Delta E^{*} a b$ within the specification, which wastes powder, as well as increasing the material cost. However, thicker coating does not ensure that $\Delta E^{*} a b$ is within the specification. When the coated film is very thick, $\Delta E^{*} a b$ is far from zero. This is due to the fact that the thicker coating film grows to the dark color after reaching the optimum point. Figure 7 shows that for the samples that have a thickness within the specification, $\Delta E^{*} a b$ was not higher than 1.0. Thus the thickness was increased when the value was close to zero. This shows that both characteristics are interconnected.

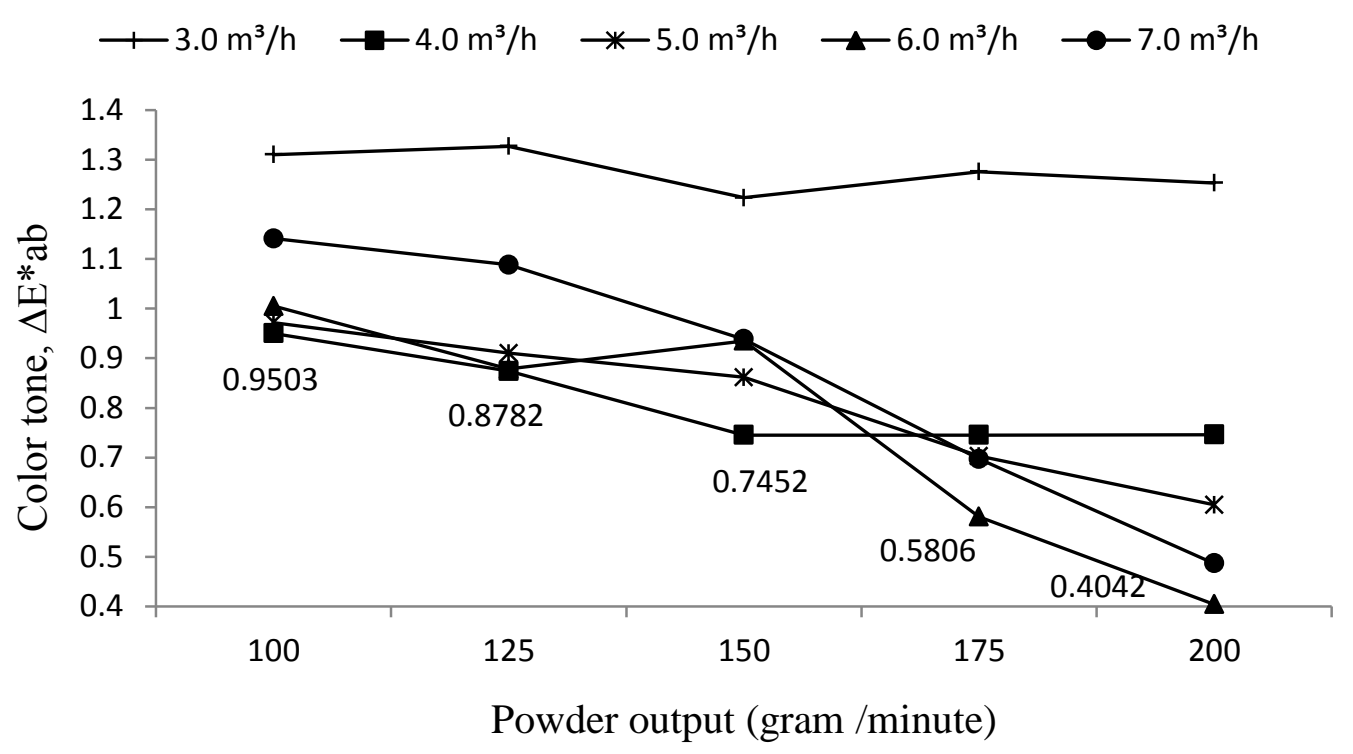

Figure 7. Color visual $\left(\Delta E^{*} a b\right)$ for combinations of powder output and total air volume. 


\section{Effects on Particles Cross-Linking Structure using Different Combinations of Powder Output and Total Air Volume}

The particles cross-linking structure is different for each sample because it has different thickness. Good samples have a complete single layer of coating. This also optimizes the powder usage, as well as saving a lot of material cost. A double layer of coating prevents the sample from having good surface protection, while increasing the powder usage. Figure 8 shows the microstructure of the particles cross-linking structure of the coated film.

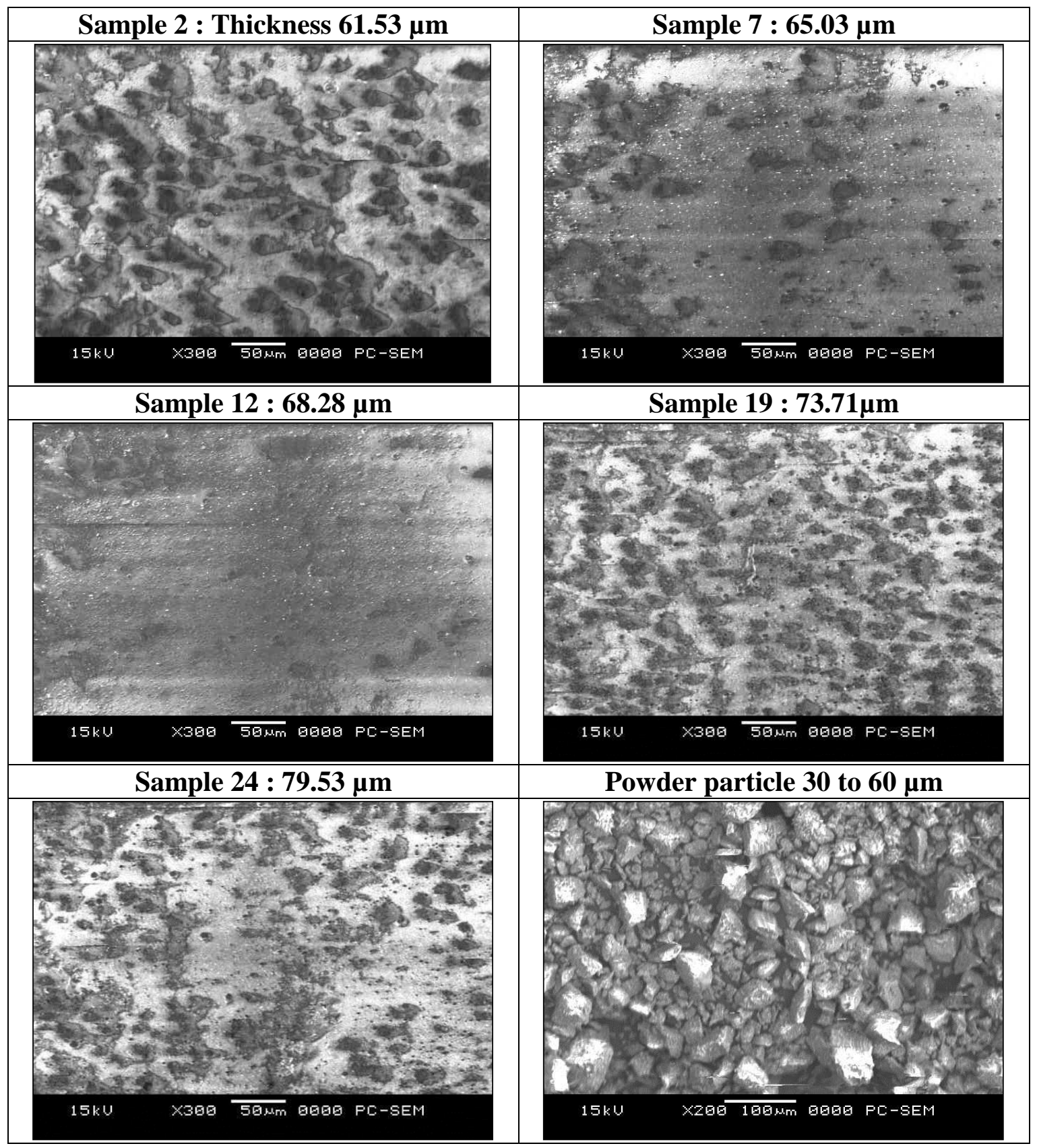

Figure 8.Microstructure of the particle cross-linking structure of the coated film. 
The particles cross-linking structure for sample 2 shows that the coating film has an incomplete single layer and insufficient powder coverage. It has much orange peel on the surface because the powder particles are not completely linked with each other. The sample surface was not smooth due to many areas having peaks and hills. It has poor surface protection. The raw material is exposed to moisture that could cause rust. Sample 7 with $65.03 \mu \mathrm{m}$ thickness also has an incomplete single layer. The sample has insufficient powder coverage. The surface texture for this sample was better than sample 2, but it still has much orange peel and a poor protection layer. Analysis from Figure 8 found that sample 12 has a good particles cross-linking structure compared with others. The film thickness for this sample was $68.28 \mu \mathrm{m}$. This shows that the sample has a complete single layer of coated film. There is no orange peel on the surface. The sample has sufficient powder coverage to protect the surface from any defect. The parameters setting for these parts was $150 \mathrm{~g} / \mathrm{min}$ powder output combined with $4.0 \mathrm{Nm}^{3} / \mathrm{h}$ total air volume. This parameter setting is suitable to be used during powder spraying to coat a large quantity of parts for mass production. Better particle cross-linking can prevent the parts from any defects and optimize the powder usage. The surface structures for samples 19 and 24 show that the coated layers have sufficient powder coverage. Some areas have started to build up a double layer of coating film. The orange peel effect was also visible on the surface. The double layer of coating can prevent the parts from corrosion and rust. However, there is poor adhesion of the coated layer to the material surface. The material cost was increased due to much powder being used to spray the sample.

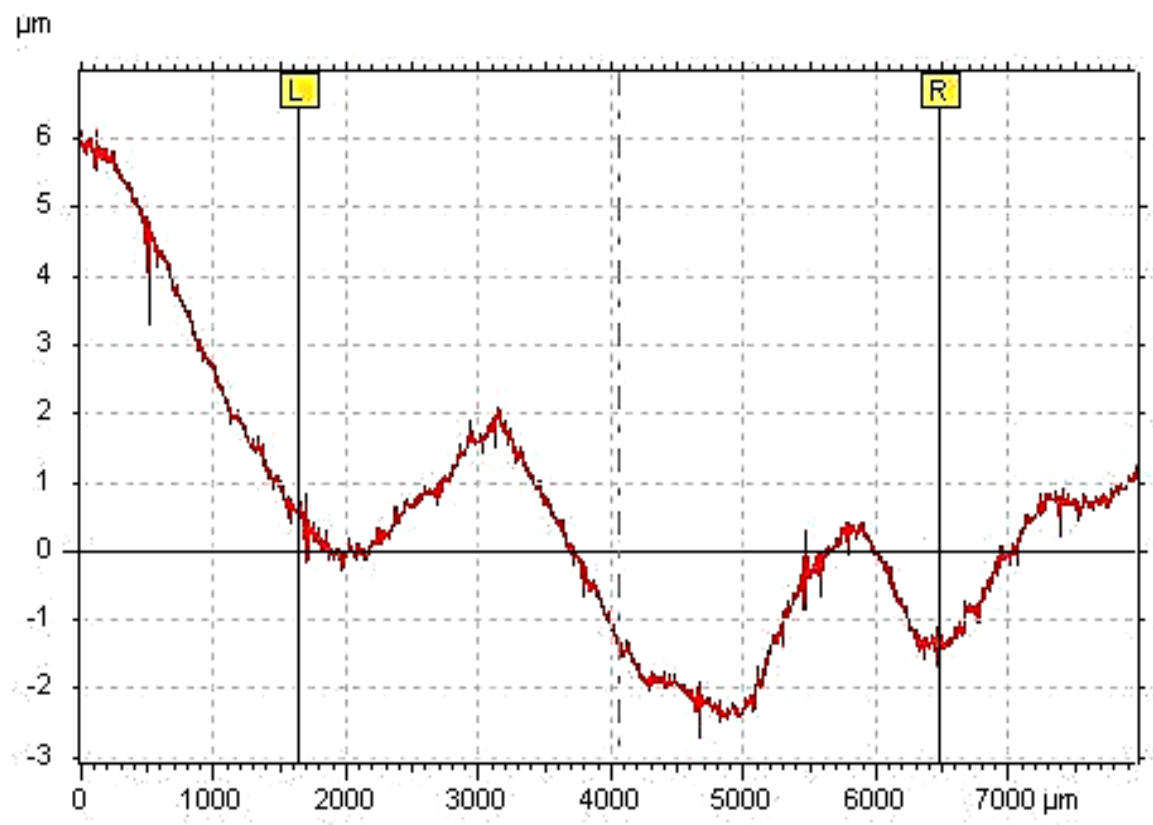

Figure 9. Surface profile for sample 2 with $61.53 \mu \mathrm{m}$ thickness.

\section{Effects on Coating Surface Texture using Different Combinations of Powder Output and Total Air Volume}

Figure 9 shows the surface profile for sample 2 with $61.53 \mu \mathrm{m}$ of film thickness. From coordinate 1650 to $6500 \mu \mathrm{m}$ (with $4850 \mu \mathrm{m}$ surface length) the difference between the higher and lower levels was $4.5 \mu \mathrm{m}$. This surface texture has an incomplete single layer. 
It can be strengthened by the result obtained from Figure 8 obtained by the SEM. The surface profile for sample 2 has significant orange peel. Orange peel is basically a surface texture of "hills and valleys". This defect is closely related to the powder flow and thickness. The powder flow must be optimum to ensure that the powder can reach and stick to the parts.

Figure 10 shows the surface profile for sample 7. This sample has $65.03 \mu \mathrm{m}$ of film thickness. The thickness and color visual value for this sample were within the specification. This shows that the surface level of the coated film was not uniformly distributed. From coordinate $1650 \mu \mathrm{m}$ to $6500 \mu \mathrm{m}$ (with $4850 \mu \mathrm{m}$ length), the difference between the higher and lower level was $\pm 4.0 \mu \mathrm{m}$. The surface profile for sample 7 was better than sample 2, but it still has an orange peel effect. It also has an incomplete single layer of coating.

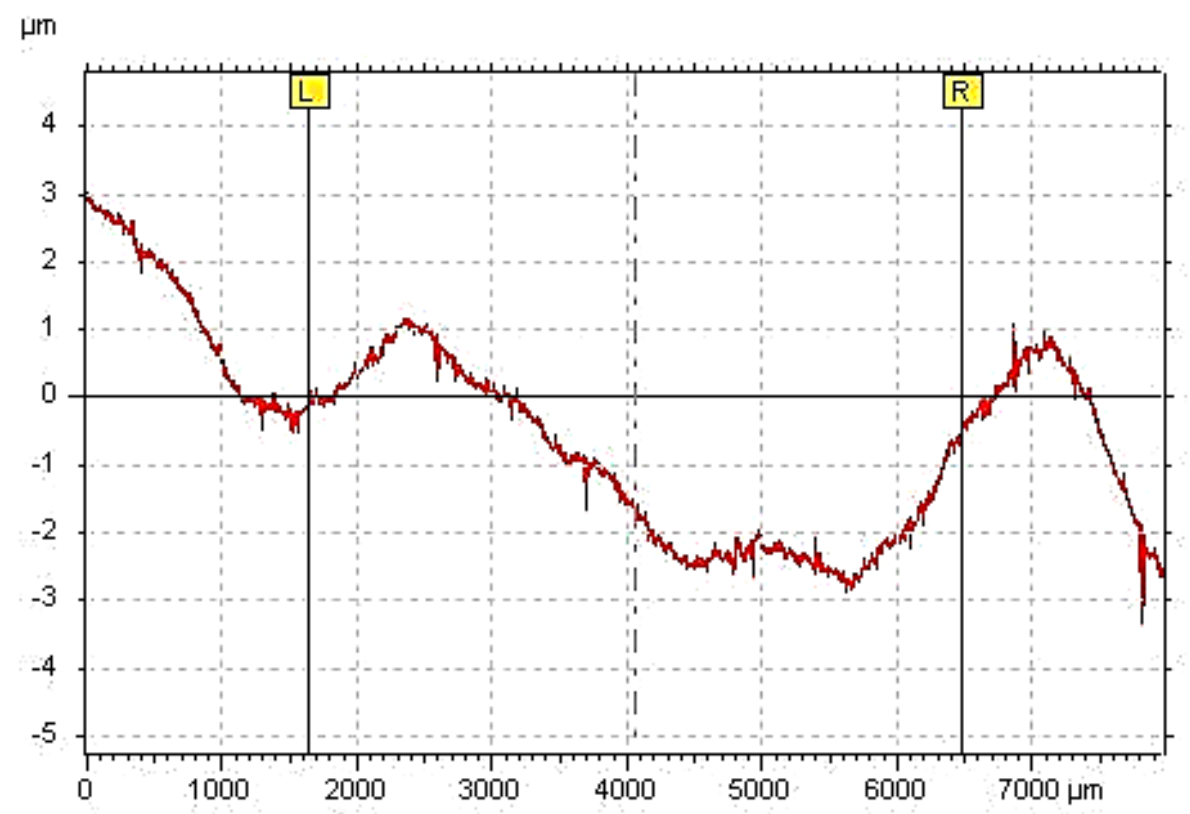

Figure 10. Surface profile for sample 7 with $65.03 \mu \mathrm{m}$ thickness.

Figure 11 shows the surface profile for sample 12. From coordinate 1750 to $6500 \mu \mathrm{m}$ (with $4750 \mu \mathrm{m}$ surface length) it has a complete single layer of coating film. The variance between high and low level was $\pm 2.0 \mu \mathrm{m}$. It can be concluded that sample 12 has an optimum combination of powder output and total air volume. The combination of these two variable parameters produced the optimum coating thickness, color visual and good surface texture. Besides, it has enough powder coverage to protect the surface from corrosion and rust. For sample 19, the coating thickness was $73.71 \mu \mathrm{m}$, which was higher than sample 12. Figure 12 shows the surface structure for sample 19, where the sample surface texture was smooth. The variance between the highest and lowest level was $\pm 7.0 \mu \mathrm{m}$. From 1650 to $6450 \mu \mathrm{m}$ (with $4800 \mu \mathrm{m}$ surface length) the sample surface has sufficient powder coverage. The orange peel effect was not obvious due to the wide range between peak and hills. This sample has a complete single layer of coating, but there are some areas with build-up to a double layer. This finding was strengthened by the result obtained from SEM. The surface was still acceptable because it was covered with powder, sufficient to protect against corrosion and rust. 


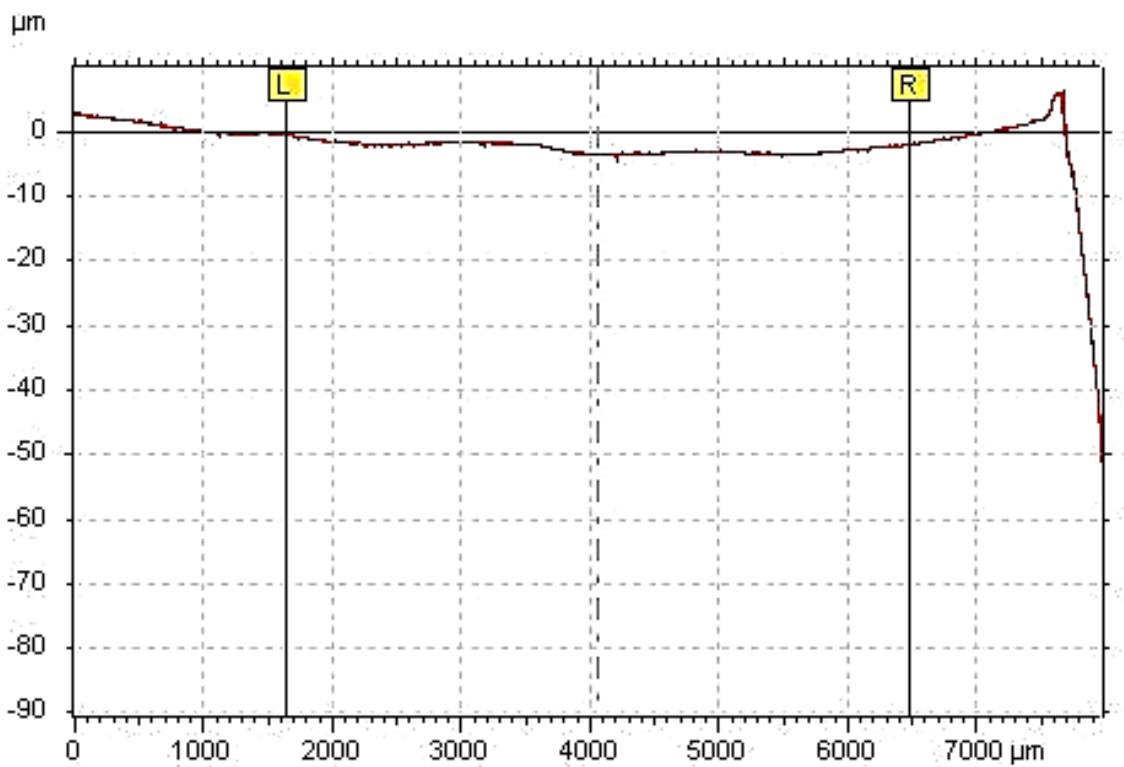

Figure 11. Surface profile for sample 12 with $68.28 \mu \mathrm{m}$ thickness.

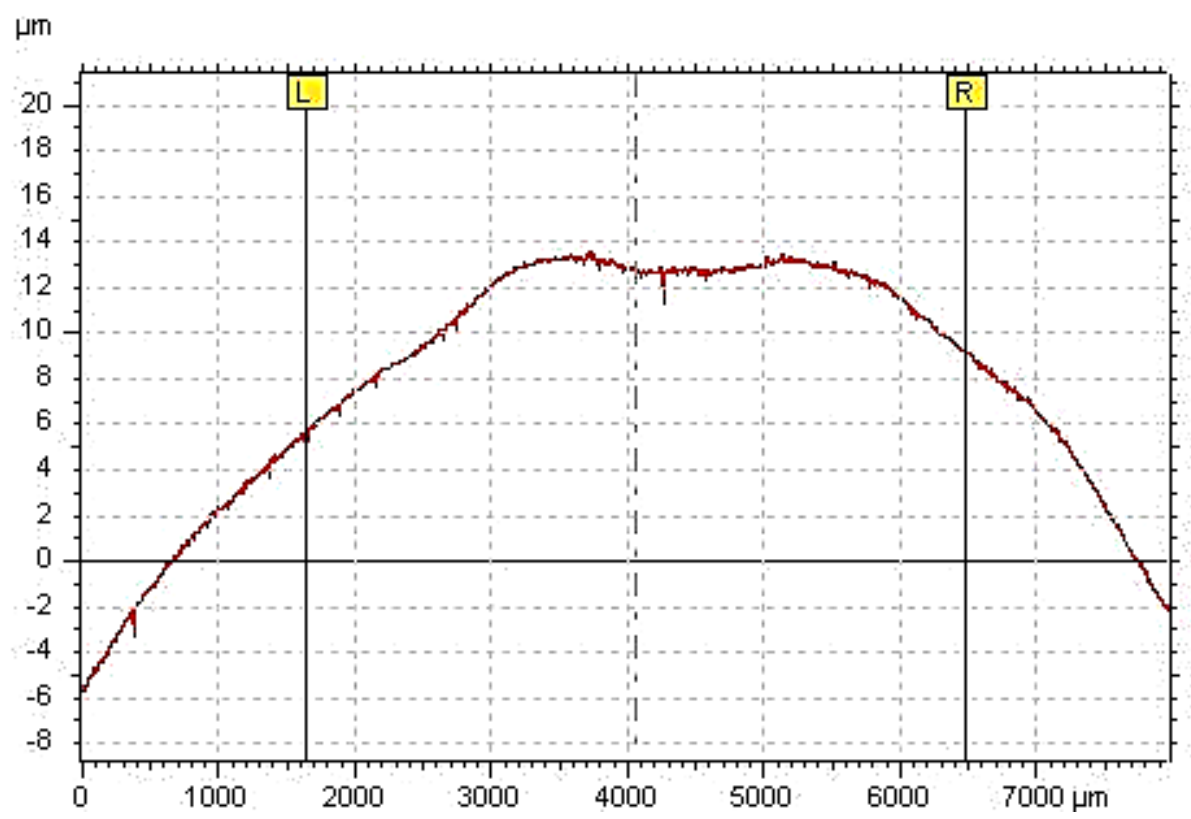

Figure 12. Surface profile for sample 19 with $73.71 \mu \mathrm{m}$ thickness.

Figure 13 shows that sample 24 has a smooth surface texture. However, the surface level was not uniform. From coordinate 1650 to $6450 \mu \mathrm{m}$, the surface profile also has a peak and hill. This means that the sample still has an orange peel effect. However, the effect was not visible because of the wide distance between the peak and hill. Many areas were covered with a double layer of powder. The double layer of coating can also produce a smooth surface texture, as well as protecting the surface from corrosion and rust. However, it caused a waste of powder because much powder was used to spray the samples. 


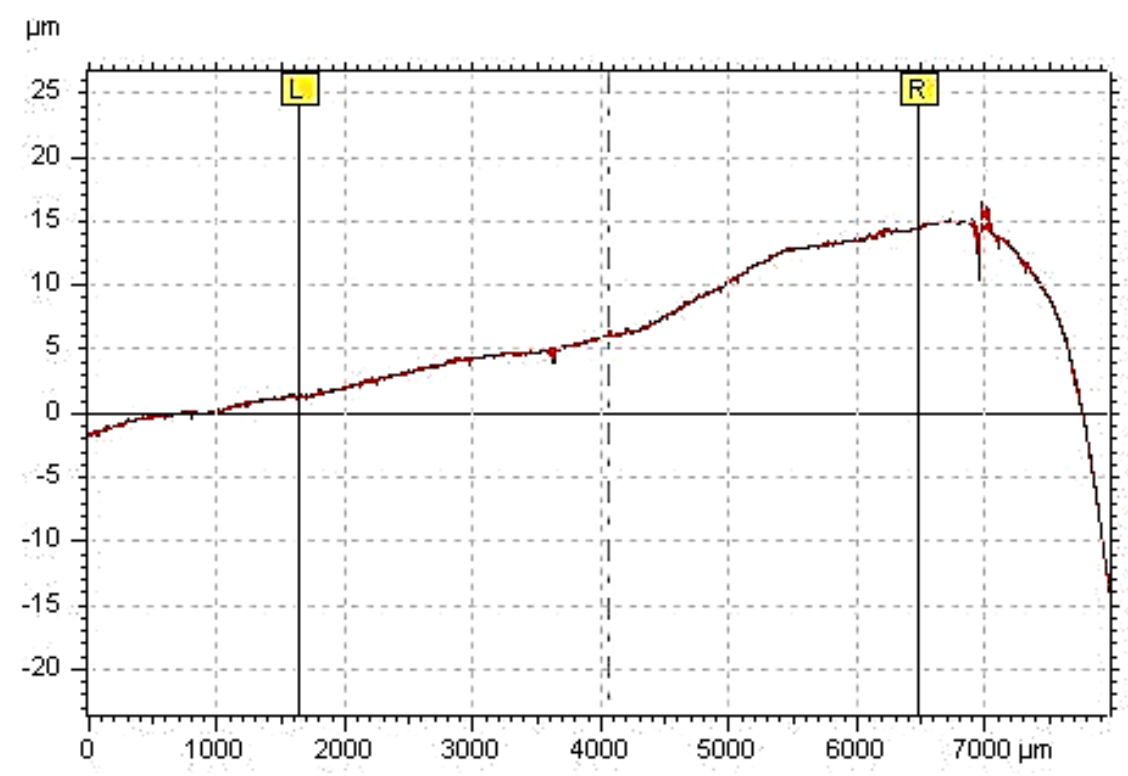

Figure 13. Surface profiles for sample 24 with $73.71 \mu \mathrm{m}$ thickness.

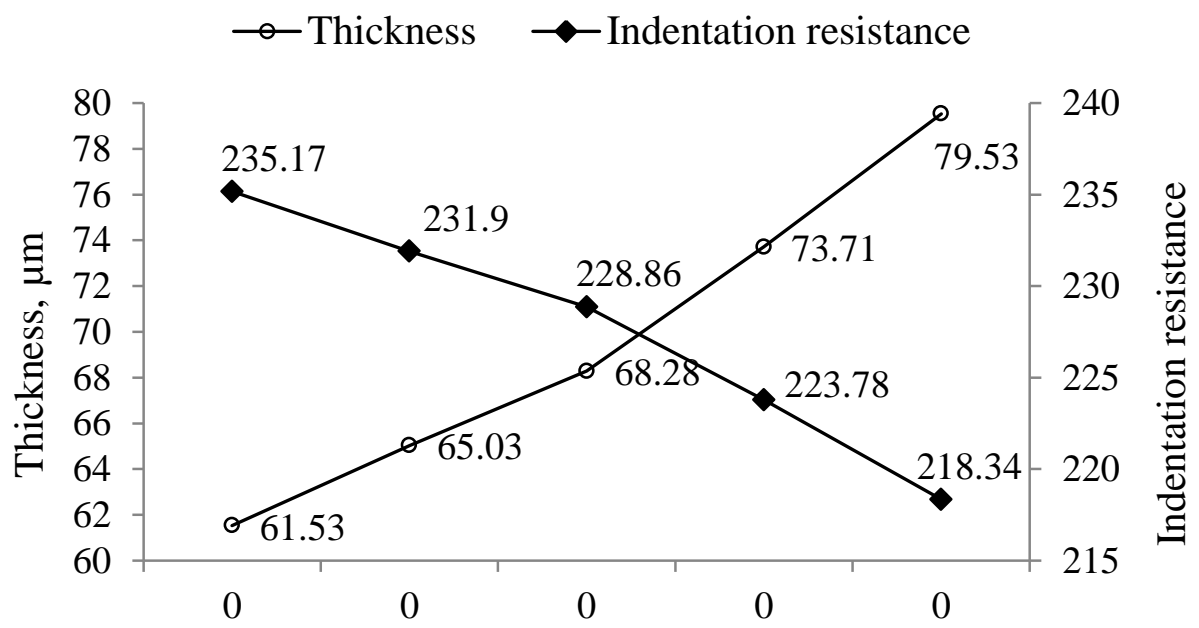

Powder output (g/min)

Figure 14. Indentation resistance for samples with optimum combinations of powder output total air volume.

\section{Effects on Indentation Resistance using Different Combinations of Powder Output and Total Air Volume}

Figure 14 shows that a thin coating has high indentation resistance compared with a thicker coating. Samples 2 and 7 have the highest indentation resistance. However, results for particle cross-linking and surface profile analysis for both samples show that they have insufficient powder coverage. This phenomenon caused the indentation resistance to increase. This is because the powder did not fully cover the material surface. The indentation resistance was based on the raw material's strength and not the coated film's strength. Indentation resistance for sample 12 was higher than samples 19 and 24. Based on the particles cross-linking structure and surface profile analysis, this 
sample has a complete single layer of coating. This shows clearly that a single layer of coating has higher indentation resistance. This is due to the fact that a complete single layer of coating has a good particle cross-linking structure. Good particle bonding protects the surface from indentation.

Table 2.Classification of the adhesion for the optimum combinations of powder output and total air volume.

\begin{tabular}{|c|c|c|c|c|c|}
\hline $\begin{array}{c}\text { Sample } \\
\text { No }\end{array}$ & $\begin{array}{c}\text { Powder } \\
\text { output } \\
\mathrm{g} / \mathrm{min}\end{array}$ & $\begin{array}{l}\text { Total air } \\
\text { volume } \\
\mathrm{Nm}^{3} / \mathrm{h}\end{array}$ & Class & Description & Appearance \\
\hline 2 & 100.0 & 4.0 & 1 & $\begin{array}{l}\text { Detachment of small flakes of } \\
\text { the coating at the intersections } \\
\text { of the cuts. A cross-cut area } \\
\text { not greater than } 5 \% \text { is } \\
\text { affected. }\end{array}$ & \\
\hline 7 & 125.0 & 4.0 & 1 & $\begin{array}{l}\text { Detachment of small flakes of } \\
\text { the coating at the intersections } \\
\text { of the cuts. A cross-cut area } \\
\text { not greater than } 5 \% \text { is } \\
\text { affected. }\end{array}$ & \\
\hline 12 & 150.0 & 4.0 & 1 & $\begin{array}{l}\text { Detachment of small flakes of } \\
\text { the coating at the intersections } \\
\text { of the cuts. A cross-cut area } \\
\text { not greater than } 5 \% \text { is } \\
\text { affected. }\end{array}$ & \\
\hline 19 & 175.0 & 6.0 & 2 & $\begin{array}{l}\text { The coating has flaked along } \\
\text { the edges at the intersections } \\
\text { of the cuts. A cross-cut area } \\
\text { not greater than } 15 \% \text { is } \\
\text { affected }\end{array}$ & \\
\hline 24 & 200.0 & 6.0 & 2 & $\begin{array}{l}\text { The coating has flaked along } \\
\text { the edges at the intersections } \\
\text { of the cuts. A cross-cut area } \\
\text { not greater than } 15 \% \text { is } \\
\text { affected }\end{array}$ & \\
\hline
\end{tabular}

\section{Effects on Coating Adhesion using Different Combinations of Powder Output and Total Air Volume}

As the thickness was increased, the adhesion decreased, as shown in Table 2. This is because thicker coating film is easier to peel off. The adhesion classification for samples 2,7 and 12 is class 1 . This shows that the coating film was affected by no more than $5 \%$ during the cross-cut test. The result obtained from the particles cross-linking structure and surface profile analysis shows that samples 2 and 7 have insufficient single layer. It is cut on the material surface. The coating film for these samples was easier to peel off, compared with sample 12. This is because certain areas of these samples have a double layer of coating film. The powder particles that build up the double layer of coating stick to the bottom layer and not to the material's surface. This made the coating film 
easier to peel off. Based on the particle cross-linking analysis, these samples do not have good particles bonding and this can cause the samples to have poor adhesion. The particles cross-linking of the coating layer affected the adhesion to the substrate [18].

\section{CONCLUSIONS}

From the experiments, it was found that as the powder output increased, the film thickness also increased. However, for each percent increment of powder output, it must be supported by enough air to ensure that the transfer efficiency is in optimum condition. As a consequence, the powder fell down when the conveying air was not sufficient to support the powder to reach the parts. On the other hand, when the conveying air was too much, it caused the air to blow off the powder deposited on the surface of the part. Both phenomena reduced the transfer efficiency. Empirical studies show that the optimum combination of powder output and total air volume produced the samples with high first pass transfer efficiency (FPTE) and good coating quality. The parameter setting was $150 \mathrm{~g} / \mathrm{min}$ of powder output combined with $4.0 \mathrm{Nm} / \mathrm{h}$ of total air volume. It produced the sample with $68.20 \mu \mathrm{m}$ of film thickness. These findings can be strengthened and reaffirmed by the result obtained from SEM and the surface profiler, where the sample has a complete single layer of coating. The surface texture was smooth and no orange peel effects were visible. The results obtained from the Buchholz indentation test and cross-cut test also show that the sample has good indentation resistance and adhesion. It is recommended for future studies to include charging efficiency as a parameter to be optimized for the electrostatic coating process.

\section{ACKNOWLEDGEMENTS}

The authors would like to thank Universiti Tun Hussein Onn Malaysia (UTHM) for supporting this research.

\section{REFERENCES}

[1] Matsui M, Takahashi T, Ito T. Improvement of the Transfer Efficiency of the Atomized Powder Coating System by Increasing the Conveying Air Speed. IEEE Transactions on Industry Applications. 2009;45:606-14.

[2] Chen H, Gatlin B, Burnside G, Reddy RN, Kandarpa VK, Mazumder MK. A transfer efficiency model for powder coating process. Industry Applications Conference IEEE.1995; 1280-3.

[3] Barmuta P, Cywiński K. Electroseparation and efficiency of deposition during electrostatic powder coating. Journal of Electrostatics. 2001;51:239-44.

[4] Takeuchi M. Improvement of charging characteristics of coating powders in electrostatic powder coating system. Journal of Physics: Conference Series: IOP Publishing; 2008. p. 012065.

[5] Shah U, Zhang C, Zhu J, Wang F, Martinuzzi R. Validation of a numerical model for the simulation of an electrostatic powder coating process. International Journal of Multiphase Flow. 2007;33:557-73.

[6] Meng X, Zhu JJ, Zhang H. Influences of different powders on the characteristics of particle charging and deposition in powder coating processes. Journal of Electrostatics. 2009;67:663-71. 
[7] Yanagida K, Morita T, Takeuchi M. A new powder flow control system for electrostatic powder coating: a closed-loop-control system equipped with a capacitance sensor. Journal of Electrostatics. 2000;49:1-13.

[8] Wang F, Martinuzzi R. Experimental study of particle trajectory in electrostatics powder coating process. Powder Technology. 2005;150:20-9.

[9] Barletta M. Combined use of scratch tests and CLA profilometry to characterize polyester powder coatings. Surface and coatings technology. 2009;203:1863-78.

[10] Cazaux J. Critical thicknesses of electrostatic powder coatings from inside. Journal of Electrostatics. 2007;65:764-74.

[11] Meng $\mathrm{X}$, Zhang $\mathrm{H}$, Zhu JJ. The characteristics of particle charging and deposition during powder coating processes with coarse powder. Journal of Physics D: Applied Physics. 2008;41:195207.

[12] Meng X, Zhu JJ, Zhang $\mathrm{H}$. The characteristics of particle charging and deposition during powder coating processes with ultrafine powder. Journal of Physics D: Applied Physics. 2009;42:065201.

[13] Shah U, Zhu J, Zhang C, Nother J. Numerical investigation of coarse powder and air flow in an electrostatic powder coating process. Powder Technology. 2006;164:22-32.

[14] Lam T. Numerical Simulation of Corona-Charging Powder Coating System: The University of Western Ontario London; 1998.

[15] Sharmene Ali F, Inculet II. Electric field analysis of the tribocharged fluidized bed powder coating process. IEEE Transactions on Industry Applications. 2000;36:1247-50.

[16] Barletta M, Gisario A, Guarino S, Tagliaferri V. Fluidized bed coating of metal substrates by using high performance thermoplastic powders: Statistical approach and neural network modelling. Engineering Applications of Artificial Intelligence. 2008;21:1130-43.

[17] Dastoori K, Makin B, Tan GL. Measurement of the electrostatic powder coating properties for corona and triboelectric coating guns. Journal of Electrostatics. 2005;63:545-50.

[18] Dastoori K, Makin B, Chye M. Adhesion measurements for electrostatic powder coatings using a vertical drop test rig and LabVIEW software. Journal of Electrostatics. 2005;63:551-7. 